\title{
Dihydroartemisinin inhibits endothelial cell migration via the TGF-ק1/ALK5/SMAD2 signaling pathway
}

\author{
LING GUO $^{1,2}$, XIAOQING WEN ${ }^{3}$, YINGLONG HOU ${ }^{1}$, RONG SUN $^{4}$, \\ LIANG ZHANG ${ }^{5}$, FUHONG LIU ${ }^{2}$ and JU LIU ${ }^{2}$
}

\begin{abstract}
${ }^{1}$ Department of Cardiology, Shandong Provincial Qianfoshan Hospital, Shandong Medicine and Health Key Laboratory of Cardiac Electrophysiology and Arrhythmia, Shandong University; ${ }^{2}$ Laboratory of Microvascular Medicine, Medical Research Center, Shandong Provincial Qianfoshan Hospital, Shandong University, Jinan, Shandong 250014; ${ }^{3}$ Department of Clinical Medicine, Weifang Medical University, Weifang, Shandong 261042;

${ }^{4}$ Advanced Medical Research Institute, The Second Hospital, Cheeloo College of Medicine, Shandong University;

${ }^{5}$ Shandong Provincial Key Laboratory of Animal Resistance Biology, Institute of Biomedical Sciences, College of Life Sciences, Shandong Normal University, Jinan, Shandong 250014, P.R. China
\end{abstract}

Received September 1, 2020; Accepted March 12, 2021

DOI: $10.3892 /$ etm.2021.10141

\begin{abstract}
Anti-angiogenesis therapy is a novel treatment method for malignant tumors. Endothelial cell (EC) migration is an important part of angiogenesis. Dihydroartemisinin (DHA) exhibits strong anti-angiogenic and anti-EC migration effects; however, the underlying molecular mechanisms are yet to be elucidated. The TGF- $\beta 1 /$ activin receptor-like kinase 5 (ALK5)/SMAD2 signaling pathway serves an important role in the regulation of migration. The present study aimed to explore the effects of DHA treatment on EC migration and the TGF- $\beta 1 / A L K 5 / S M A D 2$ signaling pathway. The effects of DHA on human umbilical vein EC migration were assessed using wound healing and Transwell assays. The effects of DHA on the TGF- $\beta 1 /$ ALK5/SMAD2 signaling pathway were detected using western blotting. DHA exhibited an inhibitory effect on EC migration in the wound healing and Transwell assays. DHA treatment upregulated the expression levels of ALK5 and increased the phosphorylation of SMAD2 in ECs. SB431542 rescued the inhibitory effect of DHA during EC migration. DHA inhibited EC migration via the TGF- $\beta 1 /$ ALK5/SMAD2-dependent signaling pathway, and DHA may be a novel drug for the treatment of patients with malignant tumors.
\end{abstract}

Correspondence to: Dr Ju Liu, Laboratory of Microvascular Medicine, Medical Research Center, Shandong Provincial Qianfoshan Hospital, Shandong University, 766 Jingshi Road, Jinan, Shandong 250014, P.R. China

E-mail: ju.liu@sdu.edu.cn

Key words: angiogenesis, dihydroartemisinin, endothelial cell migration, TGF- $\beta 1 /$ ALK5/SMAD2 pathway

\section{Introduction}

Angiogenesis is a process in which new blood vessels arise from pre-existing capillaries (1). It is not only fundamental to physiological processes, such as the menstrual cycle and wound healing $(2,3)$, but also the basis of the pathogenesis of tumor growth (4). Angiogenesis promotes tumor progression and metastasis (5). Anti-angiogenic therapy has been approved as a novel treatment for malignant tumors, such as medullary thyroid, non-small cell lung, renal cell and metastatic colorectal cancers (5).

Endothelial cell (EC) migration is the basis of angiogenesis (6). In the activation phase of angiogenesis, vascular permeability increases, basement membranes are degraded and ECs proliferate and migrate into the extracellular space and form the new capillary buds. These cells stop proliferating and migrating in the resolution phase, combine to form the basement membrane and facilitate vessel maturation. Finally, surrounding the newly formed vessels, mesenchymal cells are recruited and differentiate into smooth muscle cells and pericytes $(1,7)$.

Dihydroartemisinin (DHA), a derivative of artemisinin, has been identified to exert anti-angiogenic and anti-EC migration effects (8-10); however, the underlying molecular mechanism remains unclear.

TGF- $\beta 1$ is the predominant and most ubiquitous member of the TGF- $\beta$ superfamily and serves a pivotal role during angiogenesis (11). TGF- $\beta 1$ activates two type-I receptors with opposite effects in EC migration. One of the two type-I receptors is called activin receptor-like kinase 5 (ALK5). This phosphorylates SMAD2 proteins, resulting in inhibition of EC migration via the TGF- $31 /$ ALK5/SMAD2 signaling pathway (12). SB-431542, an ALK5 kinase inhibitor, blocks the inhibition of EC migration (13). In contrast to ALK5, activin receptor-like kinase 1 (ALK1), another TGF- $\beta 1$ type-I receptor, activates SMAD1/5, resulting in EC migration via the TGF-ß1/ALK1/SMAD1/5 signaling pathway $(12,14)$. 
In the present study, it was hypothesized that DHA could inhibit EC migration via the TGF- $31 /$ ALK5/SMAD2 signaling pathway. Human umbilical vein ECs (HUVECs) were treated with DHA and SB431542, followed by migration assays. The effects of DHA treatment on the TGF- $31 /$ ALK5/SMAD2 signaling pathway were assessed via western blotting.

\section{Materials and methods}

Cell culture. HUVECs were obtained from American Type Culture Collection and cultured in Dulbecco's modified Eagle's medium (DMEM) supplemented with $10 \%$ fetal bovine serum (FBS; Gibco, Thermo Fisher Scientific, Inc.) and antibiotics (100 IU/ml penicillin and $100 \mu \mathrm{g} / \mathrm{ml}$ streptomycin). The cells were cultured in humidified air at $37^{\circ} \mathrm{C}$ with $5 \% \mathrm{CO}_{2}$. DHA was obtained from Sigma-Aldrich (Merck KGaA), and SB431542 was purchased from Cell Signaling Technology, Inc. They were both dissolved at $10 \mathrm{mM}$ in dimethyl sulfoxide.

Cell proliferation assay. The anti-angiogenesis effect of DHA is dose-dependent. In our previous study, a concentration of $25 \mu \mathrm{M}$ or higher of DHA was demonstrated to reduce the growth of HUVECs significantly (15). Therefore, $25 \mu \mathrm{M}$ of DHA was used in the present study. An MTT Cell Proliferation Assay kit (cat. no. 1009365; Cayman Chemical Company) was used to evaluate cell proliferation. The cells were cultured at a density of $5 \times 10^{3}$ cells/well in a 96-well plate. The next day, $25 \mu \mathrm{M}$ DHA was added to the culture medium. Similarly, the control groups were treated with equivalent dimethyl sulfoxide. After $24 \mathrm{~h}$, MTT solution $(10 \mu \mathrm{l} ; 5 \mathrm{mg} / \mathrm{ml})$ was added to each well, followed by incubation for $4 \mathrm{~h}$. The culture medium was discarded, and dimethyl sulfoxide (150 $\mu \mathrm{l})$ was added. These steps were all performed at $37^{\circ} \mathrm{C}$. Finally, a 96-well plate reader (Molecular Devices, LLC) was used to analyze colorimetric intensity at a wavelength of $570 \mathrm{~nm}$. Each experiment was repeated three times.

Wound healing assay. Fully confluent HUVECs were starved for $2 \mathrm{~h}$ with $2 \%$ FBS (a stress growing condition) at $37^{\circ} \mathrm{C}$. Wounds were created across the monolayer of cells by scratching the surface with a sterile pipette tip. Then, $25 \mu \mathrm{M}$ DHA or $20 \mu \mathrm{M}$ SB431542 was added to the DMEM supplemented with $10 \%$ FBS, a physiological growing condition, in DHA treatment group or SB431542 treatment group, as previously described (16). Similarly, the control groups were treated with equivalent dimethyl sulfoxide. Eventually, images were captured after incubation for 0 and $24 \mathrm{~h}$ at $37^{\circ} \mathrm{C}$. ImageJ software 1.4.3 (National Institutes of Health) was used to determine cell migration at the 0 and $24 \mathrm{~h}$ time points. Cells were viewed using x100 magnification with a phase-contrast microscope (Olympus Corporation), as previously described (17).

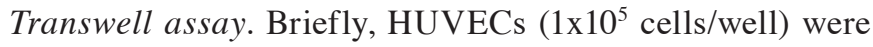
seeded in the upper chamber in 24-well plates with $25 \mu \mathrm{M} \mathrm{DHA}$ or $20 \mu \mathrm{M}$ SB431542 in DMEM supplemented with $2 \%$ FBS. Similarly, the control groups were treated with equivalent dimethyl sulfoxide. The bottom chambers were filled with $500 \mu 1 \mathrm{DMEM}$ supplemented with $10 \% \mathrm{FBS}$ overnight at $37^{\circ} \mathrm{C}$.
After $24 \mathrm{~h}$ of incubation, cells that had migrated through the membrane were fixed with $79.2 \%$ methanol and stained with $0.1 \%$ crystal violet for $30 \mathrm{~min}$ at room temperature. Migration was quantified by manually counting the number of stained cells at x200 magnification with a phase-contrast microscope (Olympus Corporation).

Western blot analysis. Western blotting was performed as previously described (17). GAPDH was used as the loading control. The following antibodies were used: Rabbit anti-TGF- $\beta$ (1:1,000; cat. no. ab66043; Abcam), rabbit anti-ALK1 (1:1,000; cat. no. ab108207; Abcam), rabbit anti-ALK5 (1:1,000; cat. no. sc-398; cat no. F0315; Santa Cruz Biotechnology, Inc.), rabbitanti-phospho-SMAD2(1:5,000; cat.no.ab188334;Abcam), rabbit anti-SMAD2 (1:5,000; cat. no. ab40855; Abcam), rabbit anti-GAPDH (1:8,000; cat. no. I0494-I-AP; ProteinTech Group, Inc.) and goat anti-rabbit IgG (1:10,000; cat. no. ab150077; Abcam).

Reverse transcription-quantitative ( $R T-q) P C R$. As previously described (18), following the addition of DMSO and DHA, HUVECs were cultured for $24 \mathrm{~h}$. HUVECs were washed twice using ice-cold PBS. The RNAiso Plus kit (Takara Bio, Inc.) was used to extract total RNA. cDNA was generated using a reverse transcriptase kit (ChamQ Universal SYBR qPCR Master Mix; cat. no. Q711-02/03; Vazyme Biotech Co., Ltd.). The total RNA $(\sim 1,000 \mathrm{ng}), 4$ x g DNA wiper Mix $(4 \mu \mathrm{l})$ and RNase-free ddH2O were incubated for 2 min at $42^{\circ} \mathrm{C}$ in A200 Gradient Thermal cycler (Thermo Fisher Scientific, Inc.). After adding 5xHiScriptIII qRT SuperMix into the aforementioned mentioned mixture, cDNA was constructed at $37^{\circ} \mathrm{C} 15 \mathrm{~min}$ and $85^{\circ} \mathrm{C}$ for $5 \mathrm{sec}$. cDNA was amplified using a Taq DNA polymerase kit (Tiangen Biotech Co., Ltd.). The qPCR reaction consisted of three steps: Pre-denaturation $\left(95^{\circ} \mathrm{C}\right.$ for $\left.30 \mathrm{sec}\right)$, cyclic reaction $\left(95^{\circ} \mathrm{C}\right.$ for $10 \mathrm{sec} ; 60^{\circ} \mathrm{C}$ for $30 \mathrm{sec}$; repeated $\mathrm{x} 40)$ and melting curve $\left(95^{\circ} \mathrm{C}\right.$ for $15 \mathrm{sec}$; $60^{\circ} \mathrm{C}$ for $60 \mathrm{sec}$; and $95^{\circ} \mathrm{C}$ for $\left.15 \mathrm{sec}\right)$. The primer sequences were as follows: ALK5 forward, 5'-GCCGTTTGACTG AAGGCTG-3' and reverse, 5'-GGGCATCCCAAGCCT CATC-3'; and GAPDH forward, 5'-TGATGACATCAAGAA GGTGGTGAAG-3' and reverse, 5'-TCCTTGGAGGCCATG TGGGCCAT-3'.

Statistical analysis. Data were expressed as mean \pm standard error (SE). $n=3$, indicated that each experiment was repeated 3 different times. Densitometric analysis of western blots was performed using Image J software 1.4.3 (National Institutes of Health). An unpaired Student's t-test or one-way ANOVA followed by the Tukey's multiple comparisons test was used for statistical analysis. Statistical analyses were performed using GraphPad Pro Prism 5.0 (GraphPad Software, Inc.). $\mathrm{P}<0.05$ was considered to indicate a statistically significant difference.

\section{Results}

$D H A$ reduces EC migration. To verify the effects of DHA on EC migration, Transwell and wound healing assays were performed. The numbers of HUVECs that migrated through the polycarbonate membrane in the Transwell assay 
A
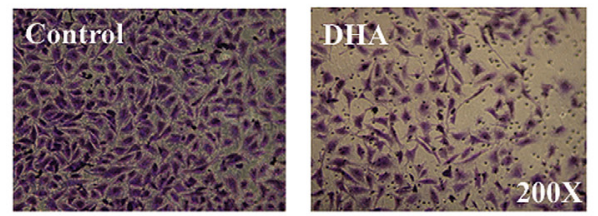

B

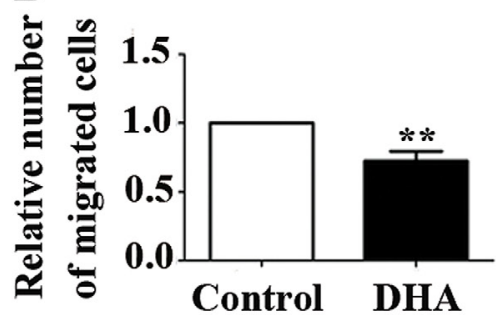

C
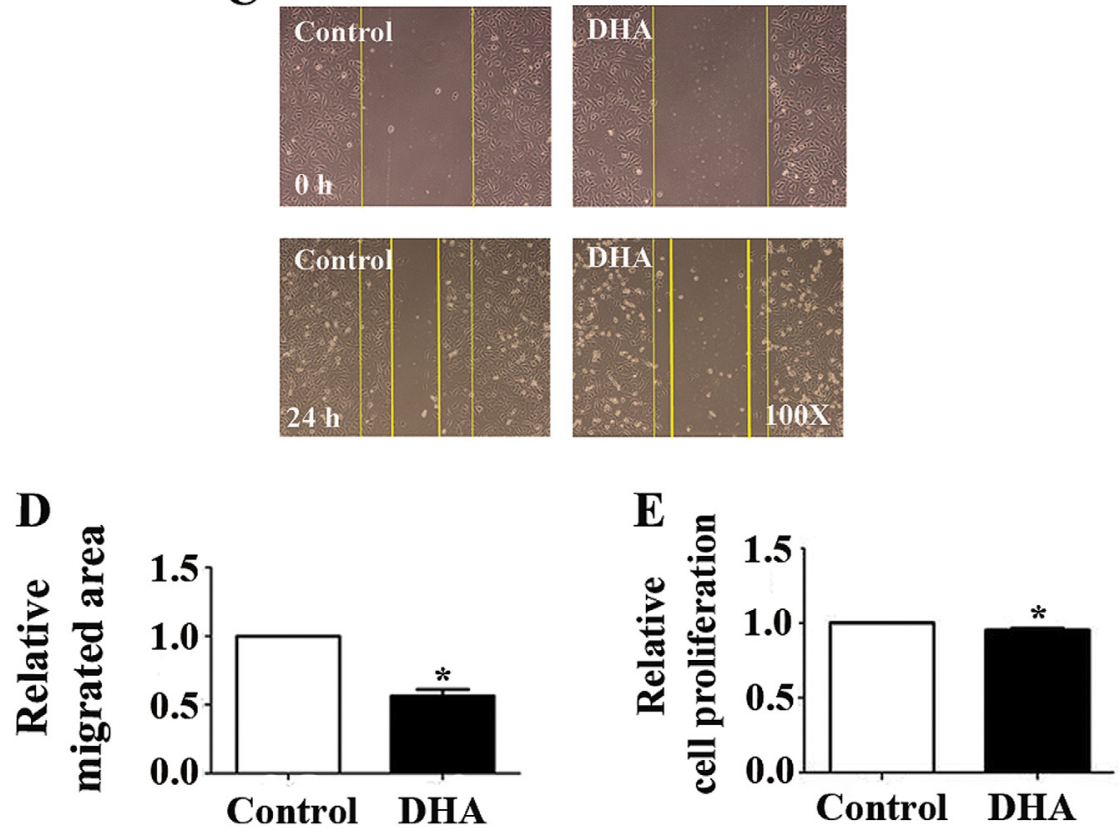

Figure 1. Cell migration and proliferation of HUVECs treated with DHA. (A) Representative cell staining images following the Transwell migration assay. (B) Relative number of cells migrating through the Transwell membrane. $n=3$. ${ }^{* *} \mathrm{P}<0.01$. (C) Representative images of the wound healing assay. Slim line indicates $0 \mathrm{~h}$ and the thick line indicates $24 \mathrm{~h}$. (D) Relative migrated area following the wound healing assay. $\mathrm{n}=3$. $\mathrm{P}<0.05$. (E) Relative cell proliferation in MTT assay. $n=3$. ${ }^{*} \mathrm{P}<0.05,{ }^{* *} \mathrm{P}<0.01$ vs. Control. DHA, dihydroartemisinin.

were significantly reduced $(33.25 \%$; $\mathrm{P}<0.01$; Fig. $1 \mathrm{~A}$ and $\mathrm{B})$. Furthermore, the area of the wound in the DHA treatment group was significantlyreduced in the wound healing assay (43.42\%; P<0.05; Fig. 1C and D). It was also demonstrated that relative cell proliferation was significantly decreased in the DHA-treated groups in the MTT assay $(4.70 \%$; $\mathrm{P}<0.05$; Fig. 1E). These data suggested that inhibitory effects of DHA on migration were more significant than those on proliferation.

DHA treatment increases the expression levels of ALK5. In order to examine the activation of two different TGF- $\beta 1$ type-I receptors in ECs, the protein expression levels of ALK1 and ALK5 were analyzed. The present study revealed significant upregulation of ALK5 protein expression in the DHA treatment group after $16 \mathrm{~h}$ of DHA treatment compared with control group (164.31\%; $\mathrm{P}<0.01$; Fig. 2A and B). However, ALK1 protein expression remained unchanged in the DHA treatment group (Fig. 2C and D). Additionally, the mRNA expression levels of ALK5 were examined, and DHA treatment upregulated ALK5 expression at the transcriptional level in the DHA treatment group (28.97\%; P<0.05; Fig. 2E). These data demonstrated that DHA-induced upregulated ALK5 expression and may not affect the ALK1/SMAD1/5 signaling pathways.

DHA treatment increases SMAD2 phosphorylation. When the TGF- $\beta 1 /$ ALK5/SMAD2 signaling pathway is activated, ALK5 phosphorylates SMAD2. The phosphorylated SMAD2 is translocated into the nucleus and activates the expression of target genes (19). Western blot analysis revealed that the levels of phosphorylated SMAD2 in the DHA treatment group were increased following DHA treatment $(97.49 \%$; $\mathrm{P}<0.05$; Fig. 3A and B). Additionally, the expression levels of SMAD2 remained unchanged in the DHA treatment group. In the presence of SB431542, the increased levels of phosphorylated SMAD2 due to DHA were partially abrogated in the DHA and SB431542 treatment groups (39.17\%; $\mathrm{P}<0.01$; Fig. 3A and B).

SB431542 rescues DHA-induced repression. SB431542 is an effective inhibitor that represses ALK5/SMAD2 phosphorylation (13). In the presence of SB431542, DHA did not inhibit EC migration, and the reduction in EC migration by DHA was rescued 
A

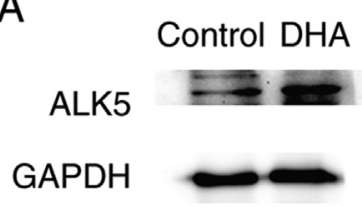

C

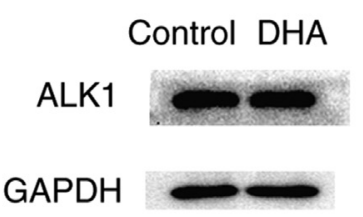

B

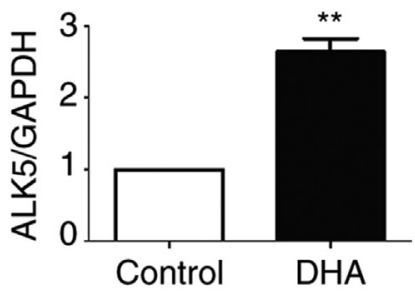

$\mathrm{D}$

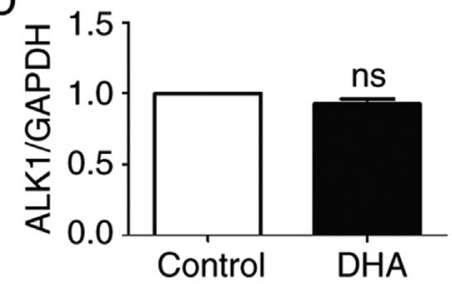

$E$

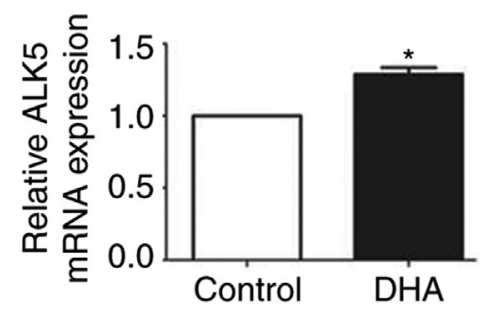

Figure 2. Effect of DHA on the expression of two distinct TGF- $\beta 1$ type I receptor. (A) Representative immunoblot of ALK5 treated with DHA. (B) Densitometric analysis of the blots of ALK5 treated with DHA. $n=3 .{ }^{* *} \mathrm{P}<0.01$. (C) Representative immunoblot of ALK1 treated with DHA. (D) Densitometric analysis of the blots of ALK1 treated with DHA. $n=3$. ns, non-significant. (E) Relative ALK5 mRNA expression in HUVEC treated with DHA. $n=3$. * $\mathrm{P}<0.05$. ns, non-significant; ALK, activin receptor-like kinase; DHA, dihydroartemisinin.

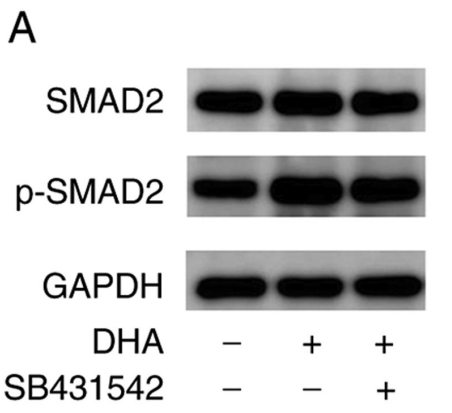

B

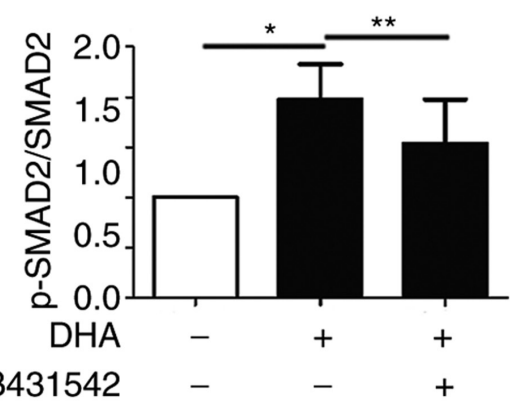

Figure 3. Effect of DHA and SB431542 on the activation of TGF- $31 / A L K 5 / S M A D 2$ in endothelial cells. (A) Representative immunoblot of SMAD2, phospho-SMAD2, and GAPDH of HUVECs treated with DHA and SB431542. (B) Densitometric analysis of the blots of phospho-SMAD2 and SMAD2 treated with DHA and SB431542.n=3. * $\mathrm{P}<0.05 ;{ }^{* *} \mathrm{P}<0.01$. p-, phosphorylated-; DHA, dihydroartemisinin; ALK, activin receptor-like kinase.

in the DHA and SB431542 treatment groups in the Transwell and wound healing assays (Fig. 4A and B). The data demonstrated that the blockade of the TGF- $\beta 1 /$ ALK5/SMAD2 signaling pathway mediated the anti-EC migration effects of DHA.

\section{Discussion}

Abnormal angiogenesis serves a crucial role in tumor survival, growth, invasion and metastasis (5). Anti-angiogenic agents, such as tyrosine kinase inhibitors, monoclonal antibodies and fusion peptides, are increasingly being used as treatments for certain malignant tumors $(20,21)$. However, the targeting of single angiogenic molecules is insufficient against the countless stimulators produced by tumors and their microenvironment.
DHA has been identified to exhibit remarkable activities, such as inhibiting angiogenesis, and inhibiting tube formation and EC migration $(15,17,22)$. The present study aimed to examine whether DHA inhibited EC migration via the TGF- $\beta 1 /$ ALK/SMAD signaling pathway. EC migration is a directional movement caused by chemotactic, haptotactic and mechanical stimuli, and it is an important part of angiogenesis (6). The dynamic and multistep process of EC migration includes cell sensing, extension, attachment, contraction, rear release and recycling movement. The whole process is affected by cytoskeletal recombination, chemokines, extracellular matrix, integrin chemotaxis, mechanical stimulation and signaling pathways (23). In our previous study, DHA exhibited dose-dependent anti-angiogenic effects, and treatment with $\geq 25 \mu \mathrm{M}$ DHA markedly reduced the proliferation of ECs (15). 
A
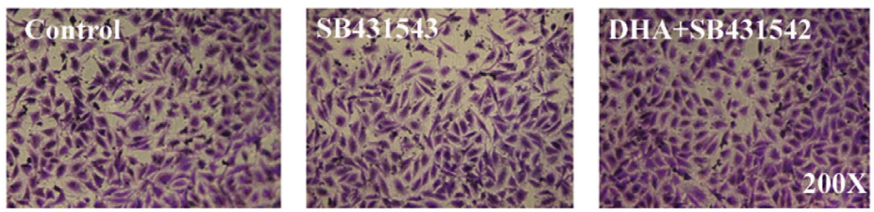

B
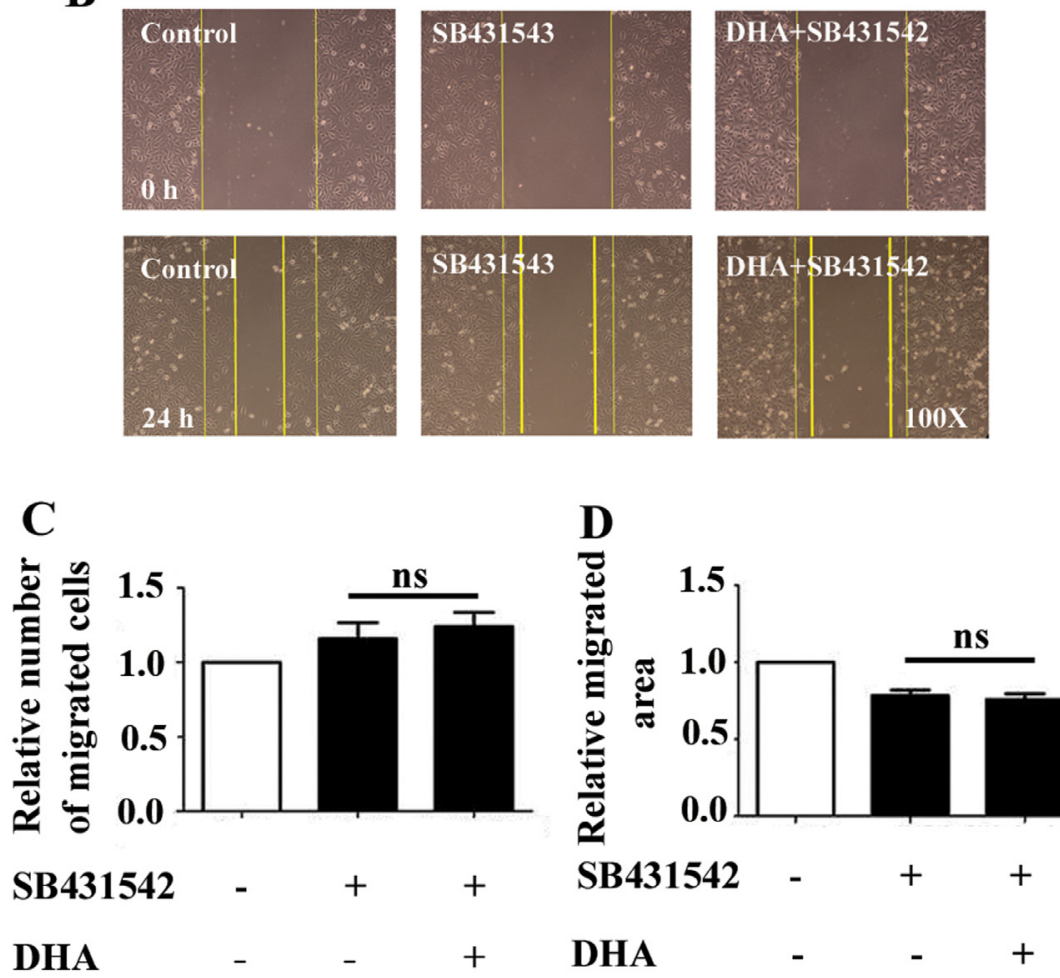

Figure 4. Effects of SB431542 on DHA-induced repression of migration. (A) Representative cell staining images following the Transwell migration assay. (B) Representative images of the wound healing assay. (C) Transwell migration assay for HUVECs treated with SB431542 in the absence or presence of DHA. $\mathrm{n}=3$. (D) Wound healing assay for HUVECs treated with SB431542 in the absence or presence of DHA. n=3. ns, not significant; DHA, dihydroartemisinin.

Consistent with our previous studies $(15,17)$, DHA treatment in the present study not only inhibited proliferation, but also inhibited migration. It was demonstrated that the inhibitory effects of DHA on migration were more significant than the effect on proliferation in the present experiments.

TGF- $\beta 1$ is primarily synthesized by platelets, dendritic cells, epithelial cells, fibroblasts, lymphocytes and macrophages/monocytes (24). TGF- $\beta 1$ is released from cells or extracellular matrix-binding protein as an inactive precursor. In the blood and tissues, TGF- $\beta 1$ is almost undetectable in its active form (25). DHA may regulate TGF- $\beta 1$ activity by increasing its synthesis and bioavailability, as reported in previous studies (26).

TGF- $\beta 1$ serves a pivotal role during angiogenesis $(11,27)$. It induces ALK1 activation, resulting in increased migration, and activates ALK5, resulting in inhibition of the migration of ECs (7). In ECs, the coexistence of the ALK1/SMAD1/5 and the ALK5/SMAD2 signaling pathways is dependent on the pattern of genes activated in a given circumstance (28). ALK1 signaling requires intact ALK 5 for activation via TGF- $\beta 1$ (14). ALK5 is required in order to recruit ALK1 into a heteromeric complex with type-II TGF- $\beta$ receptor, and ALK5 promotes ALK1 kinase activity and SMAD1/5 phosphorylation.
Additionally, SB-431542 has been demonstrated to abrogate both TGF $\beta$-induced SMAD2 and SMAD1/5 activation (14). More specifically, ALK5/SMAD2 is directly antagonized by ALK1 (14). ALK1 negatively regulates TGF- $\beta 1$ signaling by ALK5 through a promoter construct, p3TP-Lux, which contains multiple copies of the TGF- $\beta 1$ response elements in human hepatoblastoma cell line (HepG2) cells (29). Moreover, overexpression of wild-type or constitutively active (ca) ALK1 inhibited TGF- $\beta$ - or caALK5-induced ${ }_{12}$-luc reporter in mouse embryonic endothelial and HepG2 cells (14). However, in the present study, no significant changes in ALK1 expression levels in ECs treated with DHA were observed. DHA treatment upregulated the expression levels of ALK5 and increased the phosphorylation of SMAD2. In the presence of SB431542, DHA did not activate the TGF-B1/ALK5/SMAD2 signaling pathway or induce a decrease in EC migration. The current findings suggested that DHA inhibited EC migration via the TGF- $\beta 1 / A L K 5 / S M A D 2-d e p e n d e n t$ signaling pathway and may not influence the ALK1 signaling pathways.

The TGF- $\beta 1 / A L K 5 /$ SMAD2 signaling pathway has been reported to be upregulated by artemisinin and its derivatives (30). It may downregulate different cytokines, such as the Rho small GTPases, cell division cycle 42 and phosphoinositide 
3-kinase, to inhibit EC sensing of the motile stimuli, formation of protruding lamellipodia, cellular extension, attachment and contraction in order to inhibit EC migration (31-36).

In conclusion, the present results demonstrated that treatment with DHA inhibited EC migration via the TGF-ק1/ALK5/SMAD2 signaling pathway. These experiments may offer novel insights into the anti-angiogenic effects of DHA against malignant tumors. DHA may represent a novel drug that may improve the survival rate of patients with malignant tumors.

\section{Acknowledgements}

Not applicable.

\section{Funding}

The present study was supported by grants from the National Natural Science Foundation of China (grant no. 81873473, Traditional Chinese Medicine Research Projects of Shandong Province (grant nos. 2019-0370 and 2015-285) and the Academic Promotion Program of Shandong First Medical University (grant no. 2019QL014).

\section{Availability of data and materials}

The datasets used and/or analyzed during the current study are available from the corresponding author on reasonable request.

\section{Authors' contributions}

LG carried out the experimental work, the data collection, interpretation and preparation of the manuscript. XW carried out experimental work and the data collection and interpretation. YH participated in the design and coordination of experimental work. RS, LZ and FL participated in the study design, data collection, analysis of data and preparation of the manuscript. JL conceived the study design, the analysis and interpretation of data , drafted the manuscript, and gave final approval of the version to be published. LG and XW confirmed the authenticity of all the raw data. All authors read and approved the final version of the manuscript.

\section{Ethics approval and consent to participate}

Not applicable.

\section{Patient consent for publication}

Not applicable.

\section{Competing interests}

The authors declare that they have no competing interests.

\section{References}

1. Carmeliet P: Mechanisms of angiogenesis and arteriogenesis. Nat Med 6: 389-395, 2000.

2. Knighton DR, Silver IA and Hunt TK: Regulation of wound-healing angiogenesis-effect of oxygen gradients and inspired oxygen concentration. Surgery 90: 262-270, 1981.
3. Reynolds LP, Killilea SD and Redmer DA: Angiogenesis in the female reproductive system. FASEB J 6: 886-892, 1992.

4. Weidner N, Carroll PR, Flax J, Blumenfeld W and Folkman J: Tumor angiogenesis correlates with metastasis in invasive prostate carcinoma. Am J Pathol 143: 401-409, 1993.

5. Al-Abd AM, Alamoudi AJ, Abdel-Naim AB, Neamatallah TA and Ashour OM: Anti-angiogenic agents for the treatment of solid tumors: Potential pathways, therapy and current strategies-A review. J Adv Res 8: 591-605, 2017.

6. Klagsbrun $M$ and Moses MA: Molecular angiogenesis. Chem Biol 6: R217-R224, 1999.

7. Goumans MJ, Valdimarsdottir G, Itoh S, Rosendahl A, Sideras P and ten Dijke P: Balancing the activation state of the endothelium via two distinct TGF-beta type I receptors. EMBO J 21: 1743-1753, 2002.

8. Crespo-Ortiz MP and Wei MQ: Antitumor activity of artemisinin and its derivatives: From a well-known antimalarial agent to a potential anticancer drug. J Biomed Biotechnol 2012: 247597, 2012.

9. Wei T and Liu J: Anti-angiogenic properties of artemisinin derivatives (review). Int J Mol Med 40: 972-978, 2017.

10. Chen HH, Zhou HJ, Wang WQ and Wu GD: Antimalarial dihydroartemisinin also inhibits angiogenesis. Cancer Chemother Pharmacol 53: 423-432, 2004.

11. Pepper MS: Transforming growth factor-beta: Vasculogenesis, angiogenesis, and vessel wall integrity. Cytokine Growth Factor Rev 8: 21-43, 1997.

12. Goumans MJ, Lebrin F and Valdimarsdottir G: Controlling the angiogenic switch: A balance between two distinct TGF-b receptor signaling pathways. Trends Cardiovasc Med 13: 301-307, 2003.

13. Liu Z, Kobayashi K, van Dinther M, van Heiningen $\mathrm{SH}$, Valdimarsdottir G, van Laar T, Scharpfenecker M, Löwik CW, Goumans MJ, Ten Dijke P and Pardali E: VEGF and inhibitors of TGFbeta type-I receptor kinase synergistically promote blood-vessel formation by inducing alpha5-integrin expression. J Cell Sci 122: 3294-3302, 2009.

14. Goumans MJ, Valdimarsdottir G, Itoh S, Lebrin F, Larsson J, Mummery C, Karlsson S and ten Dijke P: Activin receptor-like kinase (ALK)1 is an antagonistic mediator of lateral TGFbeta/ALK5 signaling. Mol Cell 12: 817-828, 2003.

15. Dong F, Zhou X, Li C, Yan S, Deng X, Cao Z, Li L, Tang B, Allen TD and Liu J: Dihydroartemisinin targets VEGFR2 via the NF- $\mathrm{BB}$ pathway in endothelial cells to inhibit angiogenesis. Cancer Biol Ther 15: 1479-1488, 2014.

16. Martins MD, Silveira FM, Webber LP, Wagner VP, Martins MAT, Squarize CH and Castilho RM: The impact of photobiomodulation therapy on the biology and behavior of head and neck squamous cell carcinomas cell lines. J Photochem Photobiol B 209: 111924, 2020.

17. Guo L, Dong F, Hou Y, Cai W, Zhou X, Huang AL, Yang M, Allen TD and Liu J: Dihydroartemisinin inhibits vascular endothelial growth factor-induced endothelial cell migration by a p38 mitogen-activated protein kinase-independent pathway. Exp Ther Med 8: 1707-1712, 2014.

18. Livak KJ and Schmittgen TD: Analysis of relative gene expression data using real-time quantitative PCR and the 2(-Delta Delta C(T)) method. Methods 25: 402-408, 2001.

19. Derynck R, Zhang Y and Feng XH: Smads: Transcriptional activators of TGF-beta responses. Cell 95: 737-740, 1998.

20. Hurwitz H, Fehrenbacher L, Novotny W, Cartwright T, Hainsworth J, Heim W, Berlin J, Baron A, Griffing S, Holmgren E, et al: Bevacizumab plus irinotecan, fluorouracil, and leucovorin for metastatic colorectal cancer. N Engl J Med 350: 2335-2342, 2004.

21. Ilhan-Mutlu A, Osswald M, Liao Y, Gömmel M, Reck M, Miles D, Mariani P, Gianni L, Lutiger B, Nendel V, et al: Bevacizumab prevents brain metastases formation in lung adenocarcinoma. Mol Cancer Ther 15: 702-710, 2016.

22. Gao P, Wang LL, Liu J, Dong F, Song W, Liao L, Wang B, Zhang W, Zhou X, Xie Q, et al: Dihydroartemisinin inhibits endothelial cell tube formation by suppression of the STAT3 signaling pathway. Life Sci 242: 117221, 2020.

23. Horwitz R and Webb D: Cell migration. Curr Biol 13: R756-R759, 2003.

24. Krzemien S and Knapczyk P: Current review on the role of transforming growth factor beta (TGF-beta) in some pathological disorders. Wiad Lek 58: 536-539, 2005 (In Polish).

25. Huang FY, Mei WL, Li YN, Tan GH, Dai HF, Guo JL, Wang H, Huang YH, Zhao HG, Zhou SL and Lin YY: Toxicarioside A inhibits tumor growth and angiogenesis: Involvement of TGF- $\beta /$ endoglin signaling. PLoS One 7: e50351, 2012. 
26. Kajdaniuk D, Marek B, Borgiel-Marek H and Kos-Kudła B Transforming growth factor $\beta 1$ (TGF $\beta 1$ ) in physiology and pathology. Endokrynol Pol 64: 384-396, 2013.

27. Jiang Y,Zhou X, Hu R and Dai A: TGF- $\beta 1$-induced SMAD2/3/4 activation promotes RELM- $\beta$ transcription to modulate the endothelium-mesenchymal transition in human endothelial cells. Int J Biochem Cell Biol 105: 52-60, 2018.

28. Byfield SD and Roberts AB: Lateral signaling enhances TGF-beta response complexity. Trends Cell Biol 14: 107-111, 2004.

29. Oh SP, Seki T, Goss KA, Imamura T, Yi Y, Donahoe PK, Li L, Miyazono K, ten Dijke P, Kim S and Li E: Activin receptor-like kinase 1 modulates transforming growth factor-beta 1 signaling in the regulation of angiogenesis. Proc Natl Acad Sci USA 97: 2626-2631, 2000.

30. LiT, Chen H, YangZ, Liu XG,Zhang LMand Wang H: Evaluation of the immunosuppressive activity of artesunate in vitro and in vivo. Int Immunopharmacol 16: 306-312, 2013.

31. van Nieuw Amerongen GP, Koolwijk P, Versteilen A and van Hinsbergh VW: Involvement of RhoA/Rho kinase signaling in VEGF-induced endothelial cell migration and angiogenesis in vitro. Arterioscler Thromb Vasc Biol 23: 211-217, 2003 .
32. Qi JH and Claesson-Welsh L: VEGF-induced activation of phosphoinositide 3-kinase is dependent on focal adhesion kinase. Exp Cell Res 263: 173-182, 2001.

33. Lamalice L, Le Boeuf F and Huot J: Endothelial cell migration during angiogenesis. Circ Res 100: 782-794, 2007.

34. Gong C, Stoletov KV and Terman BI: VEGF treatment induces signaling pathways that regulate both actin polymerization and depolymerization. Angiogenesis 7: 313-321, 2004.

35. Liu J, Wada Y, Katsura M, Tozawa H, Erwin N, Kapron CM, Bao G and Liu J: Rho-associated coiled-coil kinase (ROCK) in molecular regulation of angiogenesis. Theranostics 8: 6053-6069, 2018.

36. Castañares C, Redondo-Horcajo M, Magán-Marchal N, ten Dijke P, Lamas S and Rodriguez-Pascual F: Signaling by ALK5 mediates TGF-beta-induced ET-1 expression in endothelial cells: A role for migration and proliferation. J Cell Sci 120: 1256-1266, 2007

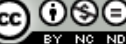

This work is licensed under a Creative Commons Attribution-NonCommercial-NoDerivatives 4.0 International (CC BY-NC-ND 4.0) License. 